\title{
POTENSI IKAN HIAS DI DANAU BATU KABUPATEN PULANG PISAU SUATU PENDEKATAN BIOLOGI DAN ETNOBIOLOGI
}

\author{
(Potential Of Ornamental Fish In Stone Lake Pulang Pisau District A Biological And \\ Ethnobiological Approach)
}

\author{
Elyta Vivi Yanti, dan Nicko Haryadi \\ Fakultas Keguruan dan Ilmu Pendidikan Universitas PGRI Palangka Raya \\ Jl. Hiu Putih, Tjilik Riwut KM.7 Palangka Raya Provinsi Kalimantan Tengah \\ email : vivielyta@gmail.com
}

Article Submitted : 03-01-2019

Article Accepted :15-01-2019

\begin{abstract}
General waters of Central Kalimantan with an area of around 2.29 million Ha is a habitat for freshwater fish, both of which have important economic value and ecological value. Diversity of fish species is a potential for fisheries production both as consumption fish, fish traded between regions and ornamental fish. Based on the latest data, there are 267 species of fish in the public waters of Central Kalimantan and 92 species of which are included in the category of ornamental fish species (Central Kalimantan Marine and Fisheries Service, 2010).Batu Lake is located in Sigi Village, Kahayan Tengah District, Pulang Pisau Regency, Central Kalimantan Province. The area of the lake is approximately $12 \mathrm{~km} 2$, around the lake there are rafts and settlements, the distance from the capital city of Kahayan Tengah Subdistrict (bukit rawi $+3 \mathrm{~km}$ where the lake slightly enters, through a small road. The distance to the lake is about $250 \mathrm{~m}$ from the road) province, the condition of the lake is still natural and only used by residents of Tuwung as a place to find livelihoods (looking for fish and other river products) as well as a means of transportation to certain areas in foodplain waters such as the Lake Batu high water fluctuations (volume of water) in a year is very large. Ruaya fish means adjustment, confidence in conditions that benefit existence and for the reproduction of species with active and sometimes passive movements from one place to another. Effendi (1997) groups the family in the interests of spawning, ruaya to enlargement and food areas and refugee homes to avoid da ri place that is in a bad condition. This research is an effort to introduce the potential of freshwater natural resources in the Lake Batu District of Pulang Pisau in the form of ornamental fish. The inventory activity will provide information about potential types of ornamental fish with all the values of their superiority or attraction so that they can become superior commodities. This research was carried out in Batu Lake $\left(2^{\circ} 08^{\prime} 23.26\right.$ "S $113^{\circ}$ 57.11'11.97" E) in Sigi Village, Kahayan Tengah District, Pulang Pisau Regency, Central Kalimantan Province. Collection is done by exploring primary and secondary data about the characteristics of biology, water quality. Water quality measurements are carried out directly in the location to obtain primary data, while secondary data is carried out through interviews with the community. The data obtained is then analyzed and explained in qualitative and quantitative descriptive so that it can provide representative information for the development of ornamental fish. The type of ornamental fish caught in the Leerii Trichogaster, Bicirrhis Cryptopterus, Rasbora Argyrotaenia, Parachela Hypophthalmus, Rasbora Caudimaculate
\end{abstract}

Keywords :Local Wisdom, Biological Aspects, Decorative fish 


\section{PENDAHULUAN}

Perairan umum Kalimantan Tengah dengan luas sekitar 2,29 juta Ha merupakan habitat bagi ikan air tawar, baik yang bernilai ekonomis penting maupun yang bernilai ekologis. Keanekaragaman jenis ikan merupakan potensi produksi perikanan baik sebagai ikan konsumsi, ikan yang diperdagangkan antar daerah maupun ikan hias. Berdasarkan data terakhir jumlah jenis ikan yang ada di perairan umum Kalimantan Tengah sebanyak 267 spesies dan 92 spesies diantaranya termasuk kategori jenis ikan hias (Dinas Kelautan dan Perikanan Provinsi Kalimantan Tengan, 2010).

Danau Batu terletak di Desa Sigi Kecamatan Kahayan Tengah Kabupaten Pulang pisau Provinsi Kalimamtan Tengah. Luas danau ini kurang lebih $12 \mathrm{~km}^{2}$, disekitar Danau terdapat rakit serta pemukiman penduduk, jarak dari ibu kota Kecamatan Kahayan Tengah (bukit rawi +3 $\mathrm{km}$ letak danau sedikit masuk kedalam, melalui jalan kecil. Ketersediaan ikan hias di alam sudah mulai terbatas, sedangkan upaya untuk melakukan budidaya sangat sulit bahkan belum dilakukan sama sekali. Sementara semakin intensifnya penangkapan ikan di alam, dikhawatirkan akan memberi dampak yang negatif terhadap kelestariannya.

Pada perairan limpasan banjir (foodplain) seperti kawasan Danau Batu fluktuasi tinggi air (volume air) dalam setahun sangat besar. Tingginya muka air dipengaruhi oleh musim kemarau dan musim penghujan, Sedangkan pada musim penghujan air meluap menutupi permukaan lahan yang luas. Perubahan tersebut berpengaruh terhadap keadaan biologi perikanan seperti produksi makanan alami, pertumbuhan, pemijahan dan ruaya berbagai jenis ikan (Yusuf dan Najamuddin, 2010). Aktivitas penangkapan ikan dan biota lainnya di perairan umum banyak melibatkan aktivitas usaha manusia (nelayan), alat tangkap, dan alam.

Pemanfaatan sumberdaya ikan hias di Danau Batu lebih banyak dilakukan dengan usaha penangkapan dengan menggunakan alat tangkap yang tidak ramah lingkungan, dengan meningkatnya upaya penangkapan ikan dan adanya kerusakan habitat, di khawatirkan potensi sumberdaya ikan khususnya ikan hias yang memiliki nilai ekonomis tinggi akan berkurang.

Penelitian ini sebagai salah satu upaya memperkenalkan potensi sumberdaya alam air tawar di Danau Batu Kabupaten Pulang Pisau berupa ikan hias.

Kegiatan inventarisasi akan memberikan informasi tentang jenis ikan hias yang potensial dengan segala nilai keunggulannya atau daya tariknya sehingga bisa menjadi komoditas unggulan.

\section{METODE PENELITIAN}

\section{Waktu dan Tempat}

Penelitiaan ini dilaksanakan di Danau Batu (2 08'23.26”S 1130 57.11'11.97'E) di Desa Sigi Kecamatan Kahayan Tengah Kabupaten Pulang Pisau Provinsi Kalimantan Tengah. Danau Batu merupakan danau oxbow yang memiliki inlet dan outlet yang berasal dari sungai Kahayan. Jarak Danau Lais dari kota Palangka Raya $\pm 10 \mathrm{~km}$ bisa ditempuh dengan menggunakan transportasi darat. 


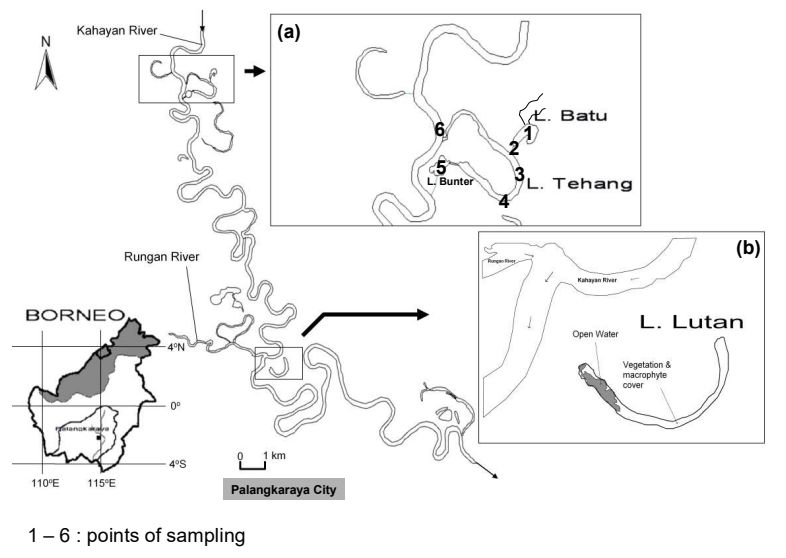

Gambar 1. Peta Lokasi Pengambilan Sampel

Tabel 1. Lokasi Sampling Kualitas Air dari pH dan suhu

\begin{tabular}{|c|c|c|}
\hline No. & Stasiun & Posisi Koordinat \\
\hline 1. & Stasiun I & $02^{0} 01^{\prime} 31.8^{\prime \prime} \mathrm{LS} 113^{0} 56^{\prime} 22.2^{\prime \prime} \mathrm{E}$ \\
\hline 2. & Stasiun II & $02^{0} 01^{\prime} 20.9^{\prime \prime} \mathrm{LS}, 113^{0} 56^{\prime} 38.2^{\prime \prime} \mathrm{E}$ \\
\hline 3. & Stasiun III & $02^{0} 01^{\prime} 31.8^{\prime \prime} \mathrm{LS} 113^{0} 56^{\prime} 22.2^{\prime \prime} \mathrm{E}$ \\
\hline 4. & Stasiun IV & $02^{0} 02^{\prime} 02.6^{\prime \prime} \mathrm{LS} 113^{0} 56^{\prime} 15.0^{\prime \prime} \mathrm{E}$ \\
\hline 5. & Statsiun V & $02^{0} 01^{\prime} 47.0^{\prime \prime} \mathrm{LS}, 113^{0} 55^{\prime} 59.5^{\prime \prime} \mathrm{E}$ \\
\hline
\end{tabular}

\section{Bahan dan Alat}

Peralatan dan bahan yang digunakan untuk penelitian ini untuk parameter kualitas air seperti suhu dan $\mathrm{pH}$ menggunakan water quality cheeker (Horiba U20), alat tulis, kamera dan alat tangkap berupa jaring atau rengge dengan ukuran mata jaring $1 \frac{1}{4}$ inchi dengan panjang 1,5 meter.

\section{Desain Penelitian}

Desain yang digunakan dalam penelitian ini adalah deskritif yaitu studi mengumpulkan informasi mengenai status suatu gejala yang menurut apa adanya pada saat penelitian di lakukan dalam hal ini untuk menemukan fakta, meneliti potensi ikan hias dengan pendekatan biologi dan etnobiologi.

\section{Metode Pengumpulan Data}

Pengumpulan dilakukan dengan mengeksplorasi data primer dan sekunder tentang karakeristik biologi, kualitas air. Pengukuran kualitas air dilakukan secara langsung dilokasi untuk memperoleh data primer, sedangkan data sekunder dilakukan dengan melaui wawancara dengan masyarakat. Data yang diperoleh lalu dianalisis dan dijelaskan secara deskriptif kualitatif maupun kuantitatif sehingga dapat memberikan informasi yang representative bagi pengembangan ikan hias. 


\section{HASIL DAN PEMBAHASAN}

Tabel 2. Kualitas Suhu dan pH Air di Danau Batu Kabupaten Pulang Pisau

\begin{tabular}{|c|c|c|c|c|c|c|c|c|c|c|c|}
\hline \multirow{2}{*}{ Sampling } & \multirow{2}{*}{$\begin{array}{c}\text { Tanggal } \\
\text { Pengamatan }\end{array}$} & \multicolumn{2}{|c|}{ Stasiun 1} & \multicolumn{2}{|c|}{ Stasiun 2} & \multicolumn{2}{|c|}{ Stasiun 3} & \multicolumn{2}{|c|}{ Stasiun 4} & \multicolumn{2}{|c|}{ Stasiun 5} \\
\hline & & $\mathrm{pH}$ & Suhu & pH & Suhu & $\mathrm{Ph}$ & Suhu & $\mathrm{pH}$ & Suhu & pH & Suhu \\
\hline Sampling I & 02 Juni 2018 & 5,58 & $30^{\circ} \mathrm{C}$ & 5,52 & $29^{\circ} \mathrm{C}$ & 5,54 & $29^{\circ} \mathrm{C}$ & 5,54 & $29,5^{\circ} \mathrm{C}$ & 5,44 & $30,2^{\circ} \mathrm{C}$ \\
\hline Sampling II & 09 Juni 2018 & 6,19 & $29,8^{\circ} \mathrm{C}$ & 5,19 & $29,9^{\circ} \mathrm{C}$ & 5,93 & $29,9^{\circ} \mathrm{C}$ & 6 & $30^{\circ} \mathrm{C}$ & 5,93 & $30^{\circ} \mathrm{C}$ \\
\hline $\begin{array}{l}\text { Sampling } \\
\text { III }\end{array}$ & 16 Juni 2018 & 5,86 & $30^{\circ} \mathrm{C}$ & 6,09 & $30^{\circ} \mathrm{C}$ & 5,8 & $29^{\circ} \mathrm{C}$ & 5,98 & $29,8^{\circ} \mathrm{C}$ & 5,98 & $30^{\circ} \mathrm{C}$ \\
\hline $\begin{array}{l}\text { Sampling } \\
\text { IV }\end{array}$ & 23 Juni 2018 & 6,19 & $29,8^{\circ} \mathrm{C}$ & 5,19 & $29,9^{\circ} \mathrm{C}$ & 5,93 & $29,9^{\circ} \mathrm{C}$ & 6 & $30^{\circ} \mathrm{C}$ & 5,93 & $30^{\circ} \mathrm{C}$ \\
\hline $\begin{array}{l}\text { Sampling } \\
\text { V }\end{array}$ & 30 Juni 2018 & 5,17 & $30^{\circ} \mathrm{C}$ & 5,98 & $30^{\circ} \mathrm{C}$ & 5,89 & $30^{\circ} \mathrm{C}$ & 5,99 & $29^{\circ} \mathrm{C}$ & 6,93 & $30^{\circ} \mathrm{C}$ \\
\hline $\begin{array}{l}\text { Sampling } \\
\text { VI }\end{array}$ & 06 Juli 2018 & 5,89 & $29,5^{\circ} \mathrm{C}$ & 5,89 & $30^{\circ} \mathrm{C}$ & 5,86 & $30^{\circ} \mathrm{C}$ & 5,96 & $30^{\circ} \mathrm{C}$ & 6,24 & $29^{\circ} \mathrm{C}$ \\
\hline $\begin{array}{l}\text { Sampling } \\
\text { VII }\end{array}$ & 14 Juli 2018 & 5,89 & $30^{\circ} \mathrm{C}$ & 5,11 & $30^{\circ} \mathrm{C}$ & 6,8 & $30^{\circ} \mathrm{C}$ & 5,9 & $30^{\circ} \mathrm{C}$ & 6,48 & $30^{\circ} \mathrm{C}$ \\
\hline $\begin{array}{l}\text { Sampling } \\
\text { VIII }\end{array}$ & 21 Juli 2018 & 5,75 & $30^{\circ} \mathrm{C}$ & 5,89 & $29,5^{\circ} \mathrm{C}$ & 6,6 & $30^{\circ} \mathrm{C}$ & 6,11 & $30^{\circ} \mathrm{C}$ & 6,38 & $29^{\circ} \mathrm{C}$ \\
\hline $\begin{array}{l}\text { Sampling } \\
\text { IX }\end{array}$ & 28 Juli 2018 & 6,08 & $30^{\circ} \mathrm{C}$ & 6,14 & $29^{\circ} \mathrm{C}$ & 6,41 & $30^{\circ} \mathrm{C}$ & 6,49 & $29,5^{\circ} \mathrm{C}$ & 6,18 & $29^{\circ} \mathrm{C}$ \\
\hline Sampling $X$ & 04 Agustus 2018 & 6,02 & $30^{\circ} \mathrm{C}$ & 6,01 & $29^{\circ} \mathrm{C}$ & 6,39 & $30^{\circ} \mathrm{C}$ & 6,07 & $29,5^{\circ} \mathrm{C}$ & 6,08 & $29^{\circ} \mathrm{C}$ \\
\hline $\begin{array}{l}\text { Sampling } \\
\mathrm{XI}\end{array}$ & 11 Agustus 2018 & 6,01 & $30^{\circ} \mathrm{C}$ & 6,01 & $29^{\circ} \mathrm{C}$ & 6,4 & $30^{\circ} \mathrm{C}$ & 6,02 & $29,5^{\circ} \mathrm{C}$ & 6,04 & $29^{\circ} \mathrm{C}$ \\
\hline $\begin{array}{l}\text { Sampling } \\
\text { XII }\end{array}$ & 18 Agustus 2018 & 6,68 & $28^{\circ} \mathrm{C}$ & 6,45 & $29^{\circ} \mathrm{C}$ & 6,48 & $30^{\circ} \mathrm{C}$ & 6,54 & $29^{\circ} \mathrm{C}$ & 6,45 & $30^{\circ} \mathrm{C}$ \\
\hline $\begin{array}{l}\text { Sampling } \\
\text { XIII }\end{array}$ & 25 Agustus 2018 & 6,45 & $28,9^{\circ} \mathrm{C}$ & 6,36 & $27^{\circ} \mathrm{C}$ & 6,22 & $29^{\circ} \mathrm{C}$ & 6,31 & $29^{\circ} \mathrm{C}$ & 6,14 & $30^{\circ} \mathrm{C}$ \\
\hline $\begin{array}{l}\text { Sampling } \\
\text { XIV }\end{array}$ & $\begin{array}{l}01 \text { September } \\
2018\end{array}$ & 6,35 & $29^{\circ} \mathrm{C}$ & 6,35 & $27^{\circ} \mathrm{C}$ & 6,18 & $29^{\circ} \mathrm{C}$ & 6,22 & $30^{\circ} \mathrm{C}$ & 6,24 & $29^{\circ} \mathrm{C}$ \\
\hline $\begin{array}{l}\text { Sampling } \\
\text { XV }\end{array}$ & $\begin{array}{l}08 \text { September } \\
2018\end{array}$ & 6,34 & $29^{\circ} \mathrm{C}$ & 6,32 & $27^{\circ} \mathrm{C}$ & 6,33 & $30^{\circ} \mathrm{C}$ & 6,22 & $29^{\circ} \mathrm{C}$ & 6,22 & $28^{\circ} \mathrm{C}$ \\
\hline
\end{tabular}

\section{Jenis-jenis Ikan Hias yang Tertangkap} Antara Lain :

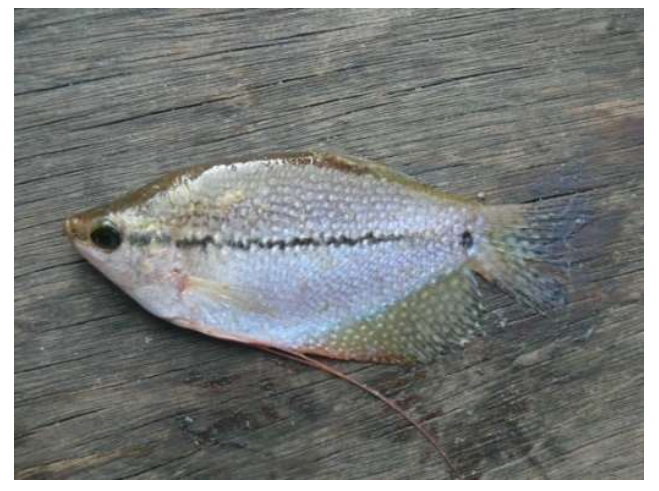

Trichogaster leerii
Klasifikasi

$\begin{array}{ll}\text { Kingdom } & : \text { Animalia } \\ \text { Filum } & \text { : Chordata } \\ \text { Kelas } & \text { : Actinopterygii } \\ \text { Ordo } & \text { : Percifomes } \\ \text { Famili } & : \text { Osphronemidae } \\ \text { Genus } & \text { : Trichogaster Leerri } \\ \text { Nama Lokal } & \text { : Sepat Layang }\end{array}$




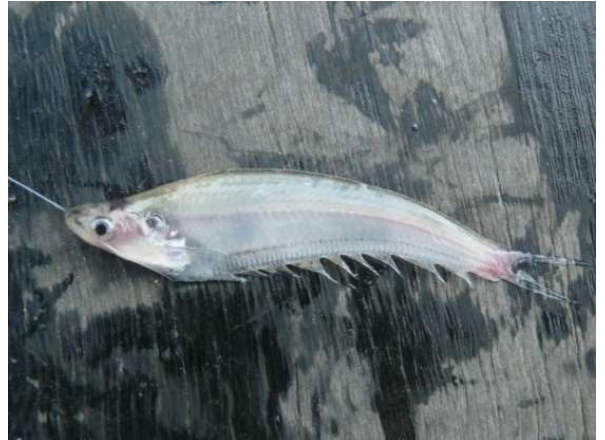

Kriptopterus bicirrhis

Klasifikasi

Kingdom : Animalia

Phylum : Chordata

Class : Actinopterygii

Order : Silurifomes

Family : Siluridae

Spesies : Kriptopterus bicirrhis

Nama Lokal : Ikan Lais Kaca

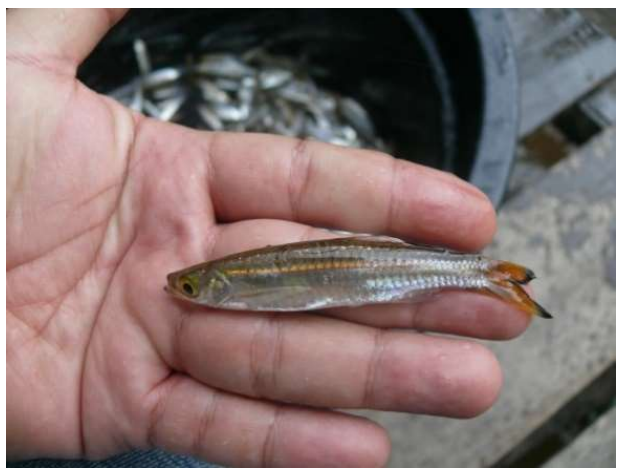

Rasbora argyrotaenia

Klasifikasi

Kingdom : Animalia

Filum : Chordata

Kelas : Actinopterygii

Ordo : Cypriniformes

Famili : Cyprinidae

Spesies: Rasbora aryrotaenia

Nama Lokal: Seluang Batu

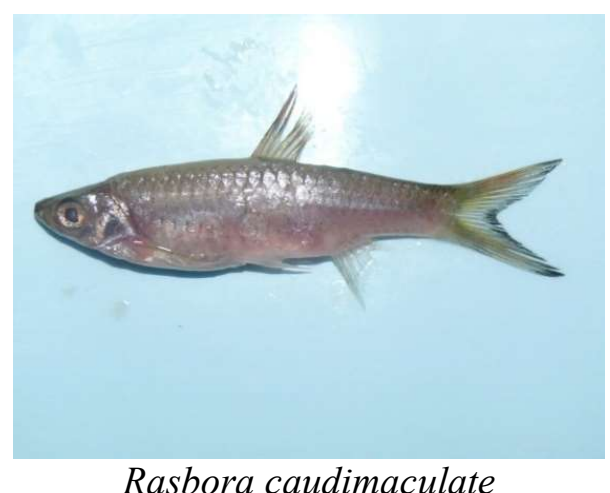

$\begin{array}{ll}\text { Klasifikasi } & \\ \text { Kingdom } & \text { : Animalia } \\ \text { Filum } & \text { : Chordata } \\ \text { Kelas } & \text { : Actinopterygii } \\ \text { Ordo } & \text { : Cypriniformes } \\ \text { Famili } & \text { : Cyprinidae } \\ \text { Spesies } & \text { : Rasbora caudimaculate } \\ \text { Nama Lokal } & \text { : Seluang }\end{array}$

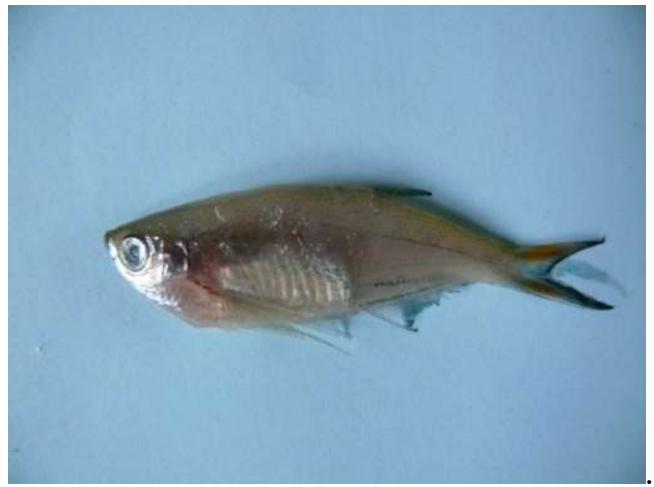

Parachela hypophthalmus

Klasifikasi

Kingdom : Animalia

Phylum : Chordata

Kelas : Actinopterygii

Ordo : Cypriniformes

Famili : Cyprinidae

Spesies : Parachela hypophthalmus

Nama Lokal : Sempirang Bulu

Keberadaan Danau Batu ini sangatlah potensial untuk kehidupan masyarakat Desa Sigi dalam memenuhi kebuhutan ikan air tawar karena itu setiap hari kebutuhan akan ikan air tawar cukup melimpah, bahkan 
keberadaan Danau Batu ini telah banyak menarik perhatian wisata alam seperti memancing.

Danau Batu sering melakukan kegiatan restocking berbagai jenis ikan, sehingga menjadikan berkembangnya biota ikan lainnya. Potensi ini mendapat perhatian dari masyarakat setempat untuk mengelola danau ini dengan baik untuk menambah pendapatan keluarga.

Upaya pendekatan kepada masyarakat untuk mengelaborasi informasi tentang jenis ikan hias juga dilakukan melalui wawancara dan penelusuran aliran Danau Batu. Selain itu, diperoleh juga informasi tentang alat tangkap yang biasa digunakan selain jaring insang(gill net) nama daerah rengge, masyarakat di sekitar Danau Batu mereka juga menggunaka alat tangkap pancing biasa, rawai, tempirai. Habitat ikan hias yang ada di Danau Batu cenderung berada di sekitar tanaman air, seperti hydrilla sp, rasau atau disekitar aliran sungai yang berarus tenang, terlindung dan ditumbuhi tanaman air.

Kualitas fisik, kimia dan biologi di suatu perairan sangat dipengaruhi oleh aktifitas yang memanfaatkan sumberdaya baik di daratan ataupun di perairan itu sendiri. Berdasarkan hasil penelitian dipeoleh informasi bahwa perairan tempat ditemukannya ikan hias merupakan daerah yang mengalami fluktusi suhu peairan yang relatif cepat, tembus cahaya matahari, serta relatif tidak dalam. Struktur perairan ini merupakan karakteristik dari daerah litoral. Pada daerah litoral, intensitas cahaya cenderung lebih banyak masuk sehingga ke dasar peraian dikarenakan perairan litoral cenderung dangkal. Pada umumnya, didaerah-daerah ini ditumbuhi tanamantanaman air dengan akar yang banyak sehingga banyak ikan-ikan kecil beraiktivitas di daerah tersebut.

Berdasarkan hasil penelitian didapatkan bahwa pada saat penelitihan ini dilaksanakan di musim kemarau, sehingga ikan hias yang ditemukan didaerah hulu dan hilir itu bermacam-macam jenis dan ikan-ikan tersebut banyak berada di daerah-daerah perairan yang ditumbuhi tanaman air dan berarus tenang.

Pertumbuhan populasi ikan dialam sangat tergantung pada strategi reproduksi dan respon terhadap perubahan lingkungan. Selama musim penghujan ikan pada umumnya memasuki perairan pedalaman sehingga ke daerah rawa-rawa melakukan pemijahan (Lisna, 2011).

Etnobilogi adalah studi ilmiah dari domain biokultur yang berkembang dalam hubungan yang dinamis antara manusia, biota, dan alam dari zaman kuno hingga saat ini (Svanberg and Luczaj, 2014). Pendekatan etnobiologi, termasuk juga etnoteknologi yang dilakukan kepada masyarakat menjadi salah satu upaya penting dalam rangka pengembangan potensi ikan hias, mulai dari aktifitas penangkapan, pengolahannya, hingga menuju aktivitas konservasi. Hubungan timbal balik dan saling membutuhkan antara manusia dan sumberdaya di lingkungannya adalah koneksi yang harus selalu berkaitan guna menjaga eksistensi lingkngan dan segala biota yang ada didalamnya. Berbagai hal yang telah dilakukan oleh masyarakat selama ini perlu mendapat dukungan dan bimbingan terkait waktu penangkapan, waktu pemijahan, pengembangan alat tangkap yang ramah lingkungan dari segi jenis maupun ukuran, serta pelestarian daerah-daerah pemijahan, nursery ground (tempat pengasuhan), maupun jalur migrasi ikan.

Ikan hias di Danau Batu pada musim kemarau dimana tidak lepas dari kebiasan masyarakat di Danau Batu menggunakan alat tangkap yang ramah lingkungan. Penggunaan jaring, tempirai, pancing yang merupakan alat tangkap bersifat pasif dengan memberikan umpan. Pada masyarakat di Danau Batu juga memiliki keraifan lokal berupa larangan untuk menangkap ikan menggunakan bahan berbahaya atau yang dapat menimbulkan risiko bagi siapapun.

Kearifan lokan yang dikemas dalam etnobiologi akan memberikan dukungan 
dalam pengembangan ikan hias, baik budidaya maupun konservasi. Selama ini, ikan-ikan hias yang tertangkap sebagian mereka jual, dan ada juga yang dikonsumsi. Namun, potensi ikan hias tidak bisa didapat dalam setiap penangkapan ikan, oleh karenanya orientasi budidaya dapat menjadikan prioritas sehingga ikan hias dapat dilestarikan. Selain itu implikasi dari kegiatan budidaya juga diharapkan adanya restocking ikan hias agar bisa lestari dan tidak punah.

Potensi ikan hias harus dikelola dengan baik berdasarkan pada kearifan lokal masyarakat. Pengelolan potensi perikanan berbasis kearifan lokal adalah salah satu alternatif manajemen yang dapat diterapkan sehingga sumber daya alam tersebut dapat dimanfaatkan secara berlanjutan (Syandri et al, 2011). Kearifan lokal terlahir sebagai suatu nilai sosial dan hukum yang berlaku dimasyarakat, berasal dari semua pengalaman empiris dan diilhami dari lingkungan, adat dan buddaya, serta kepercayaan dan sistem nilai yang berlaku di masyarakat. Pengalaman empiris akan menimbulkan kearifan ekologis yang dapat menjadi dasar untuk mewujudkan pelestarian lingkungan hidup (Hendrik, 2007).

Faktor-faktor penting yang juga mempengaruhi etnobiologi atau pengetahuan etnoikhtiologikal antara lain nilai, kelimpahan ikan, kegunaan dan sebagainya (Silvano, 2002). Pengetahuan lokal ini berperan didalam mendeterminasi suatu kebijakan yang sesuai dengan lingkungan disekitarnya. Hal yang positif dan dapat dinikmati oleh adanya hubungan harmonis dengan alam adalah pengembangan pusat endemisitas spesies termasuk dalam penyediaan bibit atau benih. Pusat-pusat di daerah sekitarnya dibangun yang memiliki keunggulan dan keunikan tersendiri. Ikan hias ini dapat memberikan manfaat yang lebih dan juga dapat menjadi faktor pendukung dan pendorong di dalam pengembangan potensi ikan hias sebagai daerah ekowisata.

\section{KESIMPULAN}

Potensi ikan hias yang terdapat di Danau Batu dapat menjadi salah satu entitas ikan air tawar di Daerah Kabupaten Pulang Pisau. Pengembangan potensi sumberdaya ikan hias dapat dilakukan melalui pendekatan kemasyarakat dengan mengedepankan kearifan etnobiologi yang telah berlangsung selam ini. Etnobiologi ikan hias dapat dikembangkan dan ditingkatkan ke arah budidaya sehingga produksi dan produktifitas ikan hias dapat di lihat sepanjang musim, tanpa harus merusak dan mengganggu eksistensi kehidupan di alam.

\section{DAFTAR PUSTAKA}

Andi M. Akhmar dan Syarifuddin, 2007. Mengungkap Kearifan Lingkungan Sulawesi Selatan, PPLH Regional Sulawesi, Maluku dan Papua, Kementerian Negara Lingkungan Hidup RI dan Masagena Press, Makasar

Astutik, Y. 2008. Analisis Ekonomi Usaha Penangkapan Ikan Lais di Danau Lais Kalimantan Tengah. Skripsi. Fakultas Pertanian Universitas Palangka Raya.

Bachtiar, Y. 2011. Budidaya Ikan Hias Air Tawar Untuk Ekspor. Cetakan I. Agromedia Pustaka. Jakarta.

Departemen Kelautan dan Perikanan 2010. Profil Sumberdaya Ikan (SDI), 14 Kabupaten/Kota Se Kalimantan Tengah.

Effendi, M.I. 2009. Biologi Perikanan. Penerbit Yayasan Pustaka Nusantara, Yogyakarta. 163 Hal.

Francis Wahono, 2005. Pangan, Kearifan Lokal dan Keanekaragaman Hayati, Penerbit Cindelaras Pustaka Rakyat Cerdas, Yogyakarta 
Frankham, R. 2006. Kuantitatif genetic in conservation biology. Genet. Res. Cam, 74 : 237-244.

Gaffar, A.K. 2007. Karakteristik Perikanan Rawa Banjiran di Sumatera Selatan. Dalam Prosiding Seminar Nasional Forum Perairan Umum Indonesia IV di Palembang $30 \quad$ November 2007. Departemen Kelautan dan Perikanan. Badan Riset Kelautan dan Perikanan . Pusat Riset Perikanan Tangkap.

Hartoto, D.I. 2000. Kriteria limnologis untuk pemilihan calon suaka perikananan perairan umum darat. Lembaga Ilmu Pengetahuan Indonesia. Pusat Penelitian Limnologi. Cibinong, Bogor.

Haslam, S.M. 2007. River Polluton and Ecologi Perspective Chichester UK. 253P.

Keraf, 2006. Etika Lingkungan. Kompas, Jakarta

Lingga, P dan Susanto, H. 2007. Ikan Hias Air Tawar. Edisi Revisi Penebar Swadaya. Bogor.

M. Ghufran. 2004. Penanggulangan Hama dan Penyakit Ikan. Penerbit Bina Adiaksara.
Nontji, A. 2004. The Status of Limnology In Indonesia Mitt Internat. Verein Limno., 24:94-113

Ondara. 2009. Pemanfaatan dan Pengelolaan Perikanan Perairan Lebak Lebung. Disampaikan dalam Temu Karya ilmiah Perikanan Perairan Umum. Pengkajian Potensi dan Prospek Pengembangan Perairan Umum Sumatera Bagian Selatan. Palembang, tanggal $12-13$ Februari 2009. Badan Penelitian dan Pengembangan Pertanian. Pusat Penelitian dan Pengembangan Perikanan. Departemen Pertanian.

Romimuhtorto. 2001. The Ecology Of Freshwater Phytoplakton. Cambridge University Press, Londn, UKM.384 P.

Tave, D. 2006. Genetic for Fish Hatchery Managers. The AVI Publ. Company, Inc. Westport, Connecticut. 299p.

Yatim. W. 2006. Genetika. Edisi kedelapan. Tersito. Bandung. 397 hal.

Yusuf, NS dan A. Najamuddin (2006). Koleksi dan inventarisasi Biologi Reproduksi Ikan Hias Langka di Perairan Umum Kalimantan Tengah. Jurusan Manajemen Sumberdaya Perairan Fakultas Pertanian Universitas Palangka Raya. 